\title{
Text Messages as a Reminder Aid and Educational Tool in Adults and Adolescents with Atopic Dermatitis: A Pilot Study
}

\author{
Venessa Pena-Robichaux, ${ }^{1,2,3}$ Joseph C. Kvedar, ${ }^{1,2,3}$ and Alice J. Watson' ${ }^{1,2,3}$ \\ ${ }^{1}$ Research Department, Center for Connected Health, 25 New Chardon Street, Suite 400D, Boston MA 02114, USA \\ ${ }^{2}$ Dermatology Department, Massachusetts General Hospital, MA 02114, USA \\ ${ }^{3}$ Department of Dermatology, Harvard Medical School, MA 02115, USA
}

Correspondence should be addressed to Venessa Pena-Robichaux, venessa.pena.robichaux@gmail.com

Received 8 June 2010; Accepted 26 July 2010

Academic Editor: Masutaka Furue

Copyright (C) 2010 Venessa Pena-Robichaux et al. This is an open access article distributed under the Creative Commons Attribution License, which permits unrestricted use, distribution, and reproduction in any medium, provided the original work is properly cited.

Optimal management of atopic dermatitis (AD) requires patients to adhere to self-care behaviors. Technologies, such as cell phones, have been widely adopted in the USA and have potential to reinforce positive health behaviors. We conducted a pilot study with 25 adolescents and adults age 14 years and older [mean 30.5 yrs, SD 13.4] with AD. Daily text messages (TMs) that provided medication reminders and AD education were sent for six weeks to participants. Our goals were to (1) measure changes in pre- and posttest scores in treatment adherence, self-care behaviors, disease severity, and quality of life and (2) assess the usability and satisfaction of the TM system. Significant improvements in treatment adherence, self-care behaviors, skin severity, and quality of life $(P \leq .001, .002,<.001$, and .014 , resp.) were noted postintervention. User feedback on the TM system was positive with $88 \%$ and $92 \%$ of participants reporting that the reminder TMs and educational TMs were helpful, respectively. In conclusion, study participants were receptive to using TMs as a reminder aid and educational tool. The positive trends observed are promising and lay the ground work for further studies needed to elucidate the full potential of this simple and cost-effective intervention.

\section{Introduction}

Atopic dermatitis (AD) is a common chronic skin disease, accounting for $30 \%$ of dermatologic consults in general practice and 10\%-20\% of dermatologists' referrals [1]. Adherence to self-care behaviors, such as taking medication regularly, amongst patients with $\mathrm{AD}$ tends to be poor [2-5]. Given the morbidity [6-11] and economic burden $[6,12,13]$ associated with $\mathrm{AD}$, it is essential that effective strategies are developed to support patients and promote self-care behaviors.

Both reminders and educational interventions have a positive impact on treatment adherence [14-18]. However, these are often delivered in a labor-intensive, costly way making them difficult to sustain or scale. The cell phone is a ubiquitous simple technology that may prove to be vital in helping to address difficulties with treatment adherence. Approximately four out of five adolescents and $89 \%$ of adults in the USA own a mobile phone $[19,20]$, and $55 \%$ of consumers utilize text messaging [21]. Text message (TM) reminders have already been used effectively to remind patients to attend medical appointments [22-24] and apply daily sunscreen [25], implicating their potential use to improve other aspects of patient adherence. Expanding the scope of TM interventions to deliver educational information in addition to reminders may prove to be an effective and affordable way to scale adherence interventions.

In this study, we evaluated the use of TMs to provide treatment adherence reminders and patient education to adolescents and adults with AD. The purpose of this pilot study was to investigate the effect of such an intervention on various parameters of treatment adherence and patient outcomes. In addition, the usability and satisfaction of the TM intervention was assessed.

\section{Methods}

2.1. Study Design. This 6-week pilot study was conducted at Massachusetts General Hospital (MGH) in Boston, MA, and 
was approved by the Partner's Healthcare human research committee. Research participants were asked to attend two study visits, one at the beginning and one at the end of the six-week study. During the first visit a trained research assistant performed a skin evaluation to assess the severity of participants' AD. After the skin evaluations participant were asked to answer questions regarding demographic information and their current $\mathrm{AD}$ treatment regimens. Participants then filled out surveys that evaluated the following: $\mathrm{AD}$ treatment adherence and utilization of $\mathrm{AD}$ self-care behaviors. During the 6 weeks following their initial visit, all study participants received a daily TM that: (1) reminded them to continue their current treatment for $\mathrm{AD}$, or (2) provided them with educational information about AD.

At the end of the 6 weeks participants returned for their final visit to $\mathrm{MGH}$, where they received a second skin evaluation and were asked to answer surveys. The surveys were identical to those at the beginning of the study except that an additional section was added, which asked participants their feedbacks about the TMs they received over the 6 weeks.

2.2. Sample. Potential research participants were recruited through advertisements placed in local newspapers and magazines as well as online (Craigslist, Facebook, http:// www.clinicaltrials.partners.org) in order to reach a diverse population. They were prescreened over the phone and were eligible to enroll if they were 14 years of age or older, had a primary care physician, had a diagnosis of $\mathrm{AD}$ that was made by their primary care physician or a dermatologist, were currently on treatment for their AD (including overthe-counter regimens), and had a cellular phone capable of receiving TMs. Twenty-nine individuals who met these criteria were identified and invited to participate in the study. Of these, 27 participants attended the first study visit, were rescreened, and gave their consent to participate (1 parent provided assent for their 16-year-old child). Two participants were dropped from the study due to changing circumstances that made them ineligible to participate, resulting in a completion rate of $93 \%(25 / 27)$.

2.3. Description of Text Message System. Research participants received a daily TM throughout the 6 weeks of the study. The daily TM alternated between providing them with a reminder to continue to their $\mathrm{AD}$ treatment and giving them educational information about $\mathrm{AD}$ (reminders were given 3 times a week, and educational information was given 4 times a week) (Figure 1). Each participant was able to choose a time frame within which they would like to receive the TM ( 7 am-9 am or 4 pm- 6 pm) and had the option of receiving an additional "fun" TM or "hook" in order to make receiving the TMs more enjoyable (participants chose between receiving the weather forecast, sports scores, or celebrity gossip). TMs were sent to participants using the TxtSignal website [26].

\subsection{Outcome Measures}

Treatment Adherence. Medication adherence was assessed at the first and last study visits in two ways. First, study participants were asked to fill out a 7-day recall calendar and mark the days during the last week when they were adherent to their AD treatment. Second, all participants were asked a multiple choice question in a survey that asked how often they forget to use their $\mathrm{AD}$ products/medication in the last week (responded "never", "once or twice", "three to five times", or "six or more"). Pre- and postintervention selfreported adherence scores were compared, using a paired $t$ test.

AD Self-Care Behaviors. A survey listing 14 behaviors (Table 3) known to help improve or prevent AD flares was developed and administered to subjects at both study visits. Participants were asked whether they exhibited these behaviors "always", "sometimes", or "never". An improvement in a self-care behavior was defined as a reported change in a positive direction (i.e., "never" to "sometimes", or "sometimes" to "always"). Pre- and postintervention selfcare behaviors were compared, using a paired $t$-test.

Skin Severity. AD severity was assessed using the SCORing Atopic Dermatitis index. A research assistant was trained on how to use this tool and performed all skin evaluations for the first and last research study visits. Pre- and postintervention SCORAD scores were compared, using a paired $t$-test.

Quality of Life. Quality of life was assessed using the Dermatology Quality of Life Index (DQLI) for those participants 17 years of age and older, and the Child Dermatology Quality of Life Index (CDQLI) for those 16 years of age and younger. Pre- and post-intervention DQLI/CDQLI scores were compared, using a paired $t$-test.

Usability and Satisfaction of Text Message System. Usability and satisfaction with the TMs was assessed via a survey administered at the final study visit. Participants were asked to rate the usefulness of the TMs, whether they would want to continue to use the TM system, if they would recommend the TM system to a friend, and if they experienced any problems with the TM system.

\section{Results}

3.1. Demographic Data. Research participants were adults and adolescents (14 years and older) currently on treatment for AD. Demographic information is presented in Table 1. The most common $\mathrm{AD}$ treatments being used by subjects at enrollment were OTC topical products (92\%), followed by prescription topical medication $(72 \%)$, oral prescription medication (12\%), and oral OTC medication (8\%).

3.2. Pre- and Postintervention Measures. Table 2 presents a summary of pre and post intervention measures. 


Text messages
Please remember to use the medication or product you
use treat your atopic dermatitis today!
and/or hay fever.
Atopic dermatitis runs in families and is thought to be
caused by a problem with your skin's ability to act like a barrier.
Atopic dermatitis typically affects the insides of elbows,
backs of knees, and the face, but can cover most of the body.
Although atopic dermatitis can develop at any age, it most
commonly develops when someone is less than 5 years old.
People with atopic dermatitis cycle through periods of
outbreaks and recovery.
People with atopic dermatitis have a lifelong tendency to
develop skin infections.
Some "trigger factors" that can cause an atopic dermatitis
flare are: pet hair, perfume, dust mites, and detergents.

Figure 1: Examples of text messages sent to subjects.

TABLe 1: Demographic characteristics of study participants.

\begin{tabular}{lc}
\hline Characteristics & $n=25$ \\
\hline Age, years (mean [SD]) & $30.5[13.4]$ \\
Gender, \% female & 72.0 \\
Ethnicity, \% & \\
$\quad$ Caucasian (nonHispanic) & 36.0 \\
Black (nonHispanic) & 28.0 \\
Hispanic & 4.0 \\
$\quad$ Asian/Pacific Islander & 12.0 \\
$\quad$ Mixed ethnicity & 20.0 \\
Education, \% & \\
$\quad$ High school or less & 20.0 \\
$\quad$ Some college & 25.0 \\
College graduate & 55.0 \\
Household income, \% less than $\$ 50,000$ & 68.0 \\
Employment, \% & \\
$\quad$ Full-time employed & 24.0 \\
Part-time employed & 20.0 \\
Student & 48.0 \\
Other* & 8.0 \\
* Other: Homemaker or Retired.
\end{tabular}

Treatment Adherence. At enrollment, the majority of subjects reported that they sometimes forget to use their $\mathrm{AD}$ medications (92\%) and often stopped their AD treatment when their skin symptoms improved (88\%). In addition, one-third of participants $(33.3 \%)$ reported that they stopped their $\mathrm{AD}$ treatment when their skin symptoms worsened. At the end of the 6-week intervention, $72 \%$ of participants reported improved adherence using both the 7 -day recall calendar (preintervention mean 3.8 days [SD 2.4], postintervention mean 6.0 days [SD 1.7], $P<.001)$ and the multiplechoice question.
Table 2: Pre- and Postintervention statistics.

\begin{tabular}{|c|c|c|c|}
\hline & Preintervention & Postintervention & $P$-Value \\
\hline \multicolumn{4}{|l|}{$\begin{array}{l}\text { Treatment } \\
\text { adherence }\end{array}$} \\
\hline $\begin{array}{l}\text { Mean number } \\
\text { of days/week of } \\
\text { adherence to } \\
\text { treatment [SD] }\end{array}$ & $3.8[2.4]$ & $6.0[1.7]$ & $<.001$ \\
\hline \multicolumn{4}{|l|}{$\begin{array}{l}\text { AD maintenance } \\
\text { Behaviors }\end{array}$} \\
\hline $\begin{array}{l}\text { Mean number } \\
\text { of behaviors } \\
\text { reported as } \\
\text { "always" } \\
\text { performing out } \\
\text { of } 14 \text { [SD] }\end{array}$ & $3.6[2.3]$ & $6.1[3.1]$ & .002 \\
\hline \multicolumn{4}{|l|}{ Skin severity } \\
\hline $\begin{array}{l}\text { Mean SCORAD } \\
\text { score }\end{array}$ & $33.4[8.9]$ & $28.2[7.7]$ & $<.001$ \\
\hline \multicolumn{4}{|l|}{ Quality of life } \\
\hline $\begin{array}{l}\text { Mean } \\
\text { CDQLI/DQLI }\end{array}$ & $7.8[5.2]$ & $5.0[3.8]$ & 0.014 \\
\hline
\end{tabular}

$A D$ Self-Care Behaviors. Over two-thirds of participants $(68 \%)$ reported an improvement in the number of behaviors they were "always" performing (pre-intervention mean 3.6/14 [SD 2.3], postintervention mean 6.1/14 [SD 3.1], $P=.002$ ). In addition, $96 \%$ of participants reported an improvement in at least one self-care behavior after the TM intervention, and half of those reported improvement in at least 5 behaviors.

Skin Severity. Overall, there was a significant improvement in SCORAD scores $(P<.001) .76 \%$ of participants had an 
TABLE 3: List of self-care behavior statements in survey.

Self-Care behavior statements*

I try to avoid heat, sweating, and dry environments

I avoid using soaps, detergents, cleaning products, and other chemicals that could irritate my skin

I avoid wearing clothing made of wool and synthetic fibers

I avoid exposure to cigarette smoke

I dust frequently to reduce exposure to dust mites

I try to find ways to decrease stress and anxiety

I avoid long (greater than 10-15 minutes) and hot baths and showers

I bathe with lukewarm water

I use a mild soap or nonsoap cleaner to remove dirt when I bathe

I apply moisturizer after I bathe

I avoid using lotions with a high water and low oil content

I control itching by using antihistamines

I cut my fingernails short to try to avoid skin damage from scratching

I use wet dressings to control my itching

*Subjects asked to respond with "always", "sometimes", or "never".

improvement in their SCORAD score (mean change in score 7.89 [SD 4.5]), and of these participants, greater than onethird $(36.8 \%)$ had an improvement $\geq 10$ points.

Quality of Life. Quality of life as assessed by DQLI/CDQLI scores significantly improved overall $(P=.014)$. $72 \%$ of participants had improvements in scores, with a mean change in score of 4.94 [SD 4.4]. Of those with an improvement in DQLI/CDQLI score, $44.4 \%$ had a change in score $\geq 5$ and $11.1 \%$ had a change in score $\geq 10$.

3.3. Usability and Satisfaction. On a scale from 1 to 10 , participants rated the usefulness of the TM system a mean score of 7.1 [SD 2.4, $\min 2, \max 10] .88 \%$ of participants reported that they found the TM reminders helpful, and $92 \%$ reported that they found the educational texts helpful. If given a choice, $84 \%$ of participants said they would want to continue using the TM system, and $84 \%$ reported they would recommend the TM system to a friend. Over two-thirds of participants $(72 \%)$ stated that they would be willing to pay a small monthly fee for this service. All participants stated that they were willing to use technology to manage their health care, and only $24 \%$ reported that they were worried about security issues of sending health information by email or phone. No problems regarding the TM system were reported.

\section{Discussion}

In this pilot study we demonstrated that text messages appear to be valuable both as a reminder aid and educational tool for subjects with AD. Subjects self-reported significant improvements in both medication adherence and self-care behaviors known to promote better clinical outcomes and quality of life. In addition, subjects expressed high levels of satisfaction with the TM intervention, with the majority willing to continue to use the service or recommend it to a friend.

As reminder aids, TMs have been proven valuable for patients in many settings [22-24, 27] and help improve adherence to treatment $[25,28]$. As such, the results from our study which illustrate improved adherence are not surprising. However, our study went a step further by integrating educational information into the TMs sent to subjects. This is something that to our knowledge has never been done, and we believe that providing patients with this additional educational information can serve as a steppingstone for the improvements in self-care behaviors that were observed in this group.

TMs can be used as an adjunct to conventional care for delivering patient education. Delivering education about AD through TMs may help patients to learn more about their skin disease and the behaviors that could help prevent flares. We believe educating patients in such a way could lead to improved attitudes towards treatment, positive changes in self-care behaviors, and improved clinical outcomes.

Studies focusing on children with $\mathrm{AD}$ have found that education can have a positive impact on clinical outcomes in these patients [14-18]. However, the educational intervention used in these cases were parental workshops, which are often time consuming and inconvenient. TMs provide a cost-effective way to deliver short, concise segments of education over a longer period of time. Using TMs to deliver patient education requires no extra effort from the providers' side, as the system is automated. In addition, results from our study suggest that patients are willing and ready to begin integrating technology, such as TMs, into their care. In addition, online automated TM platforms are now beginning to support two-way communication, which indicates that there is much potential for growth with regard to the utilization of TMs for improving communication between patients and physicians.

\section{Limitations}

The results of this study must be considered in the context of the study design. As a pilot study with no control group, the data gathered can only point to possible trends that may occur in adolescent and adult patients with $\mathrm{AD}$ should a TM intervention be implemented into their care. In addition, we cannot say whether the effects observed are related to the intervention or the effect of study participation. Our sample size was also small with majority of participants being under the age of 30 and female. Although our study results are not immediately generalizable to all patients with $\mathrm{AD}$ in the US population, they do likely represent trends that would be seen in those young individuals who would be most likely to want to integrate TMs into the delivery of their healthcare. Thus, the results described here will be useful for informing the initial implementation of such tools. Adherence to treatment in this study was measured by self-report because more objective measures, such as 
electronic adherence monitors, are cumbersome and costly. Although using self-report to measure adherence is only moderately valid [29-32], an attempt to avoid discrepancies in self-report was made by having participants both answer a multiple choice adherence question and fill out a 7day recall calendar. Finally, although the website used for sending the automated TMs could confirm that the TMs were sent to the study participants, there was no way of knowing whether or not the TMs were open and read by their recipients. However, because the feedback from the usability and satisfaction portion of the survey was primarily positive it is possible that most participants did utilize the TM service as intended.

\section{Conclusion}

This study illustrates that the use of TMs, a simple and inexpensive technology, may be effective as a reminder aid and educational tool in young patients with $\mathrm{AD}$. The implications of the possible impact of this intervention on clinical outcomes in this patient population should be confirmed by a randomized controlled trial. Further research is also needed to explore the possibility of incorporating TMs into the management of patients with other chronic dermatologic diseases (acne, psoriasis, etc.). The relatively recent revolution of cellular phones and the Internet has paved a new pathway for patient-doctor communication. Physicians must begin to utilize this technology to facilitate better delivery of education and healthcare.

\section{References}

[1] A. R. Rook, J. A. Savin, and D. S. Wilkinson, "The prevalence, incidence and ecology of diseases of the skin," in Textbook of Dermatology, A. R. Rook, D. S. Wilkinson, F. J. G. Ebling, R. H. Champion, and J. L. Burton, Eds., vol. 40, Blackwell Science, Oxford, UK, 4th edition, 1986.

[2] S. S. Zaghloul and M. J. D. Goodfield, "Objective assessment of compliance with psoriasis treatment," Archives of Dermatology, vol. 140, no. 4, pp. 408-414, 2004.

[3] H. L. Richards, D. G. Fortune, T. M. O'Sullivan, C. J. Main, and C. E. M. Griffiths, "Patients with psoriasis and their compliance with medication," Journal of the American Academy of Dermatology, vol. 41, no. 4, pp. 581-583, 1999.

[4] K. K. Brown, W. E. Rehmus, and A. B. Kimball, "Determining the relative importance of patient motivations for nonadherence to topical corticosteroid therapy in psoriasis," Journal of the American Academy of Dermatology, vol. 55, no. 4, pp. 607$613,2006$.

[5] J. Krejci-Manwaring, M. G. Tusa, C. Carroll et al., "Stealth monitoring of adherence to topical medication: adherence is very poor in children with atopic dermatitis," Journal of the American Academy of Dermatology, vol. 56, no. 2, pp. 211-216, 2007.

[6] S. Feldman, S. M. Behnam, S. E. Behnam, et al., "Involving the patient: impact of inflammatory skin disease and patientfocused care," Pediatric Allergy and Immunology, vol. 13, no. 2, pp. 84-90, 2002.

[7] J. M. Spergel and A. S. Paller, "Atopic dermatitis and the atopic march," Journal of Allergy and Clinical Immunology, vol. 112, no. 6, pp. S118-S127, 2003.
[8] Y. Iikura, C. K. Naspitz, H. Mikawa et al., "Prevention of asthma by ketotifen in infants with atopic dermatitis," Annals of Allergy, vol. 68, no. 3, pp. 233-236, 1992.

[9] J. O. Warner, "A double-blinded, randomized, placebocontrolled trial of cetirizine in preventing the onset of asthma in children with atopic dermatitis: 18 months' treatment and 18 months' posttreatment follow-up," Journal of Allergy and Clinical Immunology, vol. 109, p. 890, 2001.

[10] G. Kiebert, S. V. Sorensen, D. Revicki et al., "Atopic dermatitis is associated with a decrement in health-related quality of life," International Journal of Dermatology, vol. 41, no. 3, pp. 151158, 2002.

[11] J. C. Su, A. S. Kemp, G. A. Varigos, and T. M. Nolan, "Atopic eczema: its impact on the family and financial cost," Archives of Disease in Childhood, vol. 76, no. 2, pp. 159-162, 1997.

[12] S. R. Feldman, C. Evans, and M. W. Russell, "Systemic treatment for moderate to severe psoriasis: estimates of failure rates and direct medical costs in a north-eastern US managed care plan," Journal of Dermatological Treatment, vol. 16, no. 1, pp. 37-42, 2005.

[13] C. N. Ellis, L. A. Drake, M. M. Prendergast et al., "Cost of atopic dermatitis and eczema in the United States," Journal of the American Academy of Dermatology, vol. 46, no. 3, pp. 361370, 2002.

[14] M. Grillo, L. Gassner, G. Marshman, S. Dunn, and P. Hudson, "Pediatric atopic eczema: the impact of an educational intervention," Pediatric Dermatology, vol. 23, no. 5, pp. 428436, 2006.

[15] E. J. Moore, A. Williams, E. Manias, G. Varigos, and S. Donath, "Eczema workshops reduce severity of childhood atopic eczema," Australasian Journal of Dermatology, vol. 50, no. 2, pp. 100-106, 2009.

[16] M. J. Cork, J. Britton, L. Butler, S. Young, R. Murphy, and S. G. Keohane, "Comparison of parent knowledge, therapy utilization and severity of atopic eczema before and after explanation and demonstration of topical therapies by a specialist dermatology nurse," British Journal of Dermatology, vol. 149, no. 3, pp. 582-589, 2003.

[17] J.-M. Chavigny, F. Adiceom, C. Bernier, M. Debons, and J.-F. Stalder, "Assessment of an educational program in an "atopic school": pilot study in 40 patients," Annales de Dermatologie et de Venereologie, vol. 129, no. 8-9, pp. 1003-1007, 2002.

[18] A. Broberg, K. Kalimo, B. Lindblad, and G. Swanbeck, "Parental education in the treatment of childhood atopic eczema," Acta Dermato-Venereologica, vol. 70, no. 6, pp. 495499, 1990.

[19] "Teenagers: A Generation Unplugged," A National

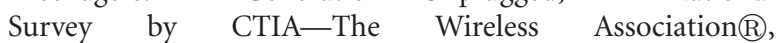
http://www.ctia.org/advocacy/research/index.cfm/AID/11483.

[20] "One in Five U.S. Adults Has No Landline," http://news.digitaltrends.com/news-article/16281/one-infive-u-s-adults-has-no-landline.

[21] "Vlingo Issues 'Consumer Text Messaging Habits' Report," http://www.reuters.com/article/pressRelease/idUS140196+21May-2008+PRN20080521.

[22] M. Geraghty, F. Glynn, M. Amin, and J. Kinsella, "Patient mobile telephone 'text' reminder: a novel way to reduce non-attendance at the ENT out-patient clinic," Journal of Laryngology and Otology, vol. 122, no. 3, pp. 296-298, 2008.

[23] Z.-W. Chen, L.-Z. Fang, L.-Y. Chen, and H.-L. Dai, "Comparison of an SMS text messaging and phone reminder to improve attendance at a health promotion center: a randomized controlled trial," Journal of Zhejiang University: Science B, vol. 9, no. 1, pp. 34-38, 2008. 
[24] K. C. Leong, W. S. Chen, K. W. Leong et al., "The use of text messaging to improve attendance in primary care: a randomized controlled trial," Family Practice, vol. 23, no. 6, pp. 699-705, 2006.

[25] A. W. Armstrong, A. J. Watson, M. Makredes, J. E. Frangos, A. B. Kimball, and J. C. Kvedar, "Text-message reminders to improve sunscreen use: a randomized, controlled trial using electronic monitoring," Archives of Dermatology, vol. 145, no. 11, pp. 1230-1236, 2009.

[26] Txtsignal, http://www.txtsignal.com/.

[27] D. A. Hanauer, K. Wentzell, N. Laffel, and L. M. Laffel, “Computerized automated reminder diabetes system (CARDS): email and SMS cell phone text messaging reminders to support diabetes management," Diabetes Technology and Therapeutics, vol. 11, no. 2, pp. 99-106, 2009.

[28] U. Strandbygaard, S. F. Thomsen, and V. Backer, "A daily SMS reminder increases adherence to asthma treatment: a threemonth follow-up study," Respiratory Medicine, vol. 104, no. 2, pp. 166-171, 2010.

[29] O. M. Minzi and A. S. Naazneen, "Validation of self-report and hospital pill count using unannounced home pill count as methods for determination of adherence to antiretroviral therapy," Tanzania Journal of Health Research, vol. 10, no. 2, pp. 84-88, 2008.

[30] S. R. Smith, A. S. Wahed, S. S. Kelley, H. S. Conjeevaram, P. R. Robuck, and M. W. Fried, "Assessing the validity of self-reported medication adherence in hepatitis C treatment," Annals of Pharmacotherapy, vol. 41, no. 7-8, pp. 1116-1123, 2007.

[31] J. L. Cohen, D. M. Mann, and J. P. Wisnivesky, "Assessing the validity of self-reported medication adherence among innercity asthmatic adults: the Medication Adherence Report Scale for Asthma," Annals of Allergy, Asthma \& Immunology, vol. 103, pp. 325-331, 2009.

[32] J. F. Conde, M. Kaur, A. B. Fleischer Jr., M. G. Tusa, F. Camacho, and S. R. Feldman, "Adherence to clocortolone pivalate cream $0.1 \%$ in a pediatric population with atopic dermatitis," Cutis, vol. 81, no. 5, pp. 435-441, 2008. 


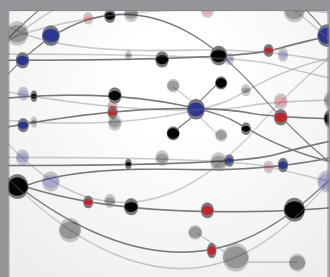

The Scientific World Journal
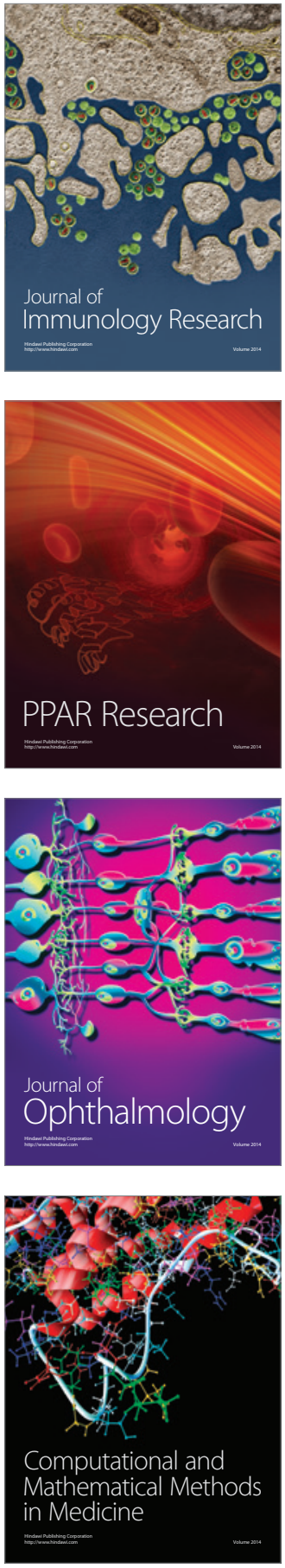

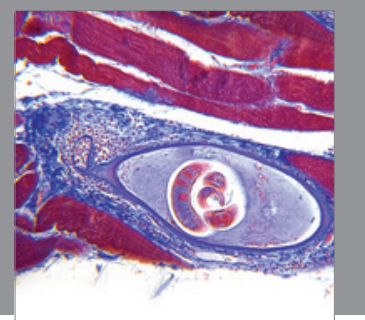

Gastroenterology

Research and Practice
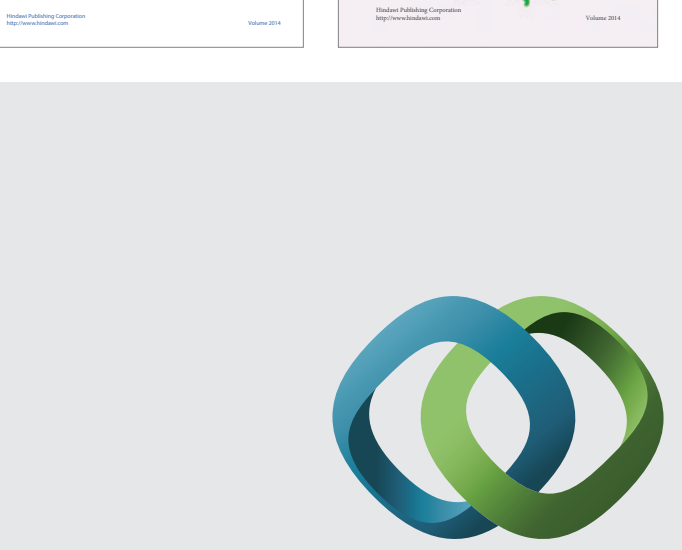

\section{Hindawi}

Submit your manuscripts at

http://www.hindawi.com
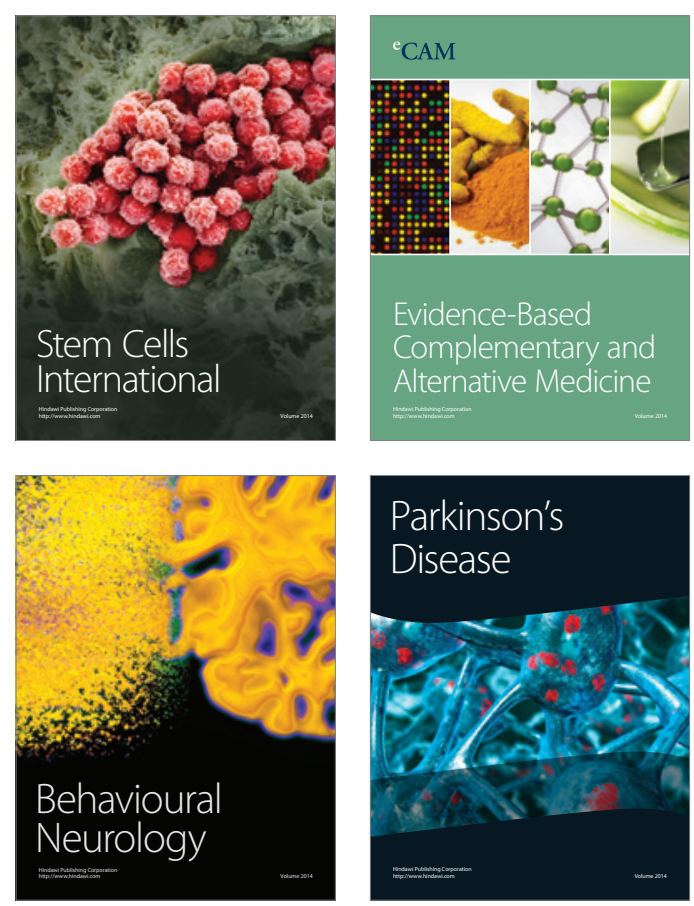

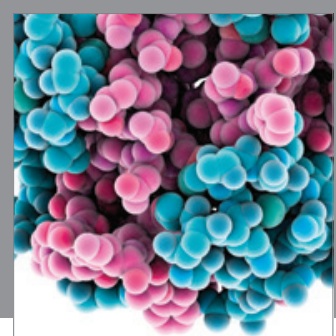

Journal of
Diabetes Research

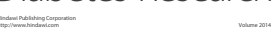

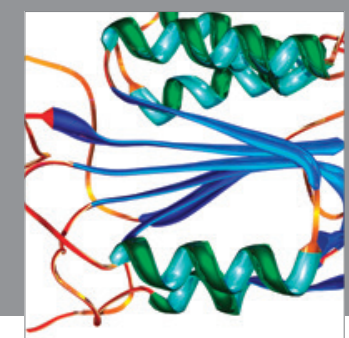

Disease Markers
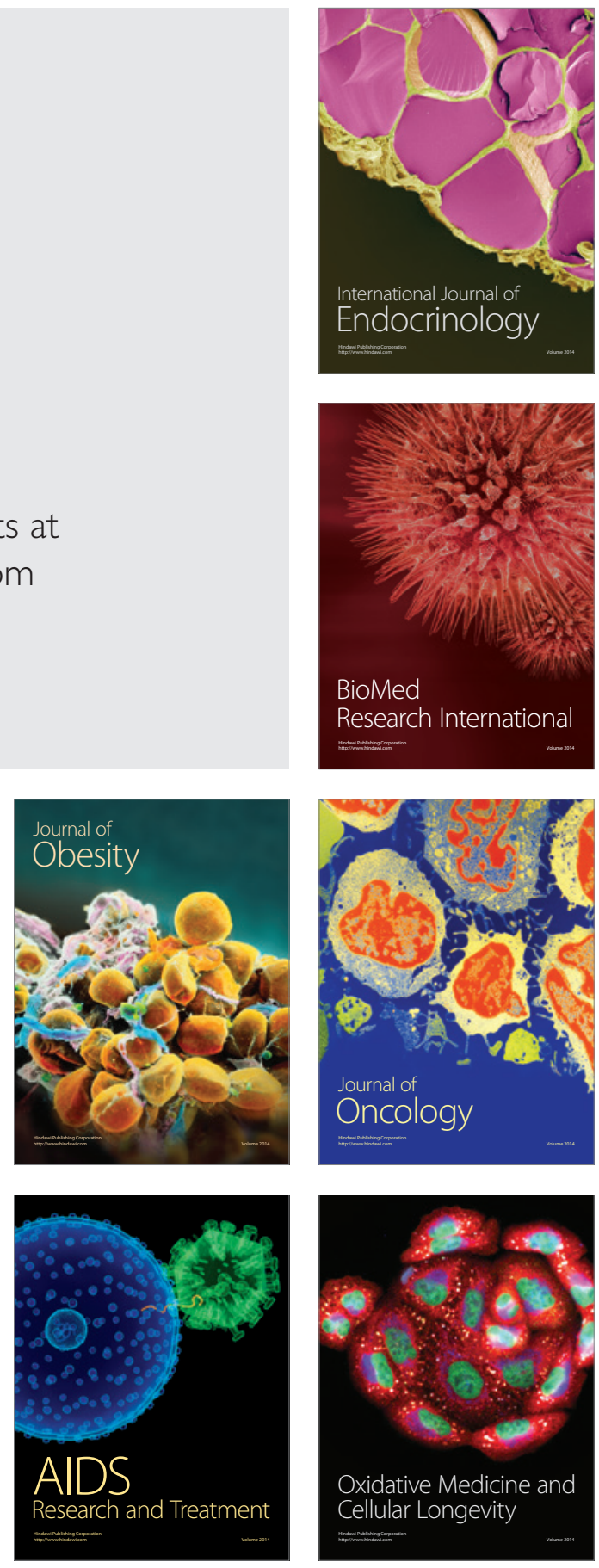